\title{
CrimRxiv
}

\section{Dissecting the Criminal \\ Corpse: Staging Post- \\ Execution Punishment in \\ Early Modern England}

\section{Elizabeth T. Hurren}

Published on: Jul 01, 2016

DOI: 10.21428/cb6ab371.4edc4aae

License: Creative Commons Attribution 4.0 International License (CC-BY 4.0). 
